http://jmscr.igmpublication.org/home/ ISSN (e)-2347-176x ISSN (p) 2455-0450 crossref DOI: https://dx.doi.org/10.18535/jmscr/v7i10.63

\title{
A Case Report of Congenital Diaphragmatic Hernia
}

\section{Authors \\ Dr Amjad Zia Mallik, Dr Kumari Ekita ${ }^{2}$, Dr Md Ashraf Ali ${ }^{3}$, Dr Sukesh Kumar ${ }^{4}$, Dr Shashank Saurav ${ }^{5}$ \\ ${ }^{1}$ Head of Department, Department of Surgery, ${ }^{2} \mathrm{PG} 3{ }^{\text {rd }}$, Department of Surgery \\ ${ }^{3}$ Senior Resident, Department of Surgery, ${ }^{4} \mathrm{PG} 22^{\text {nd }}$, Department of Surgery, ${ }^{5} \mathrm{PG} 1^{\text {st }}$, Department of Surgery}

\section{Introduction}

Congenital diaphragmatic hernia is one of the complicated cases of peadiatric surgery. Its incidence is 1:2000 to 5000 live birth. It is more common in left side then right side. Defect in closure of pleuropeitoneal canal, normally the pleural and the peritoneal cavities get separated by 8 to 10 weeks of gestation.

\section{Case Report}

A two year old male child from Katihar district had come to surgery OPD with chief complaints of recurrent vomiting for 1 month with weight loss and breathing difficulty after being referred from paediatrics.

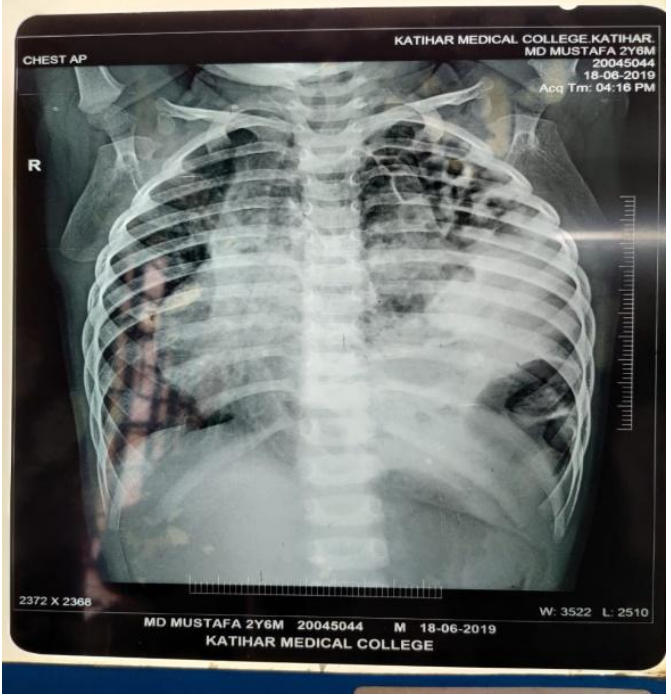

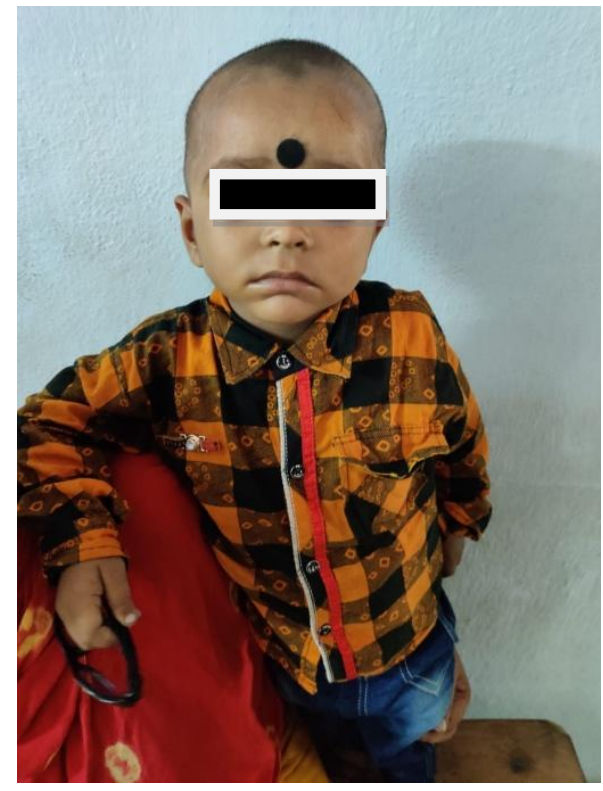

\section{Examination}

Inspection of chest wall shows presence of right sided chest protruded, rise of right side of chest wall more than left, apex beat over the right side of the chest wall in the fourth intercoastal space.

Abdomen: Scaphoid in shape

On Palpation: Vocal phremitus present in right side of the chest wall. Apex beat seen over the right side of the chest wall. Over the abdomen left hypochondrium and the left illiac fossa was empty On Percussion: Right chest wall is resonant and left chest wall is dull. 
On Auscultation: Air entry present in the right chest wall. Air entry is absent in the left side of the chest wall. S1 and S2 heard over the right side of the right chest wall. Left chest wall has low pitched gurgling sound present

Work up and Management: The patient was taken for x-ray chest it shows presence of shift of trachea to right. dextrocardia. Left chest cavity shows presence of bowel loop.

Patient was operated through left kochers incision it was found that there is a defect located anteromedially in the diaphragm. Through it first stomach then small intestine with caecum and appendix some of large intestine came out of the defect ending with spleen. The contents were then reduced into the cavity after stretching of the abdominal wall cavity. In the end chest tube was placed in the left lung. Abdomen was closed. The child revived well. His post operative phase went uneven full. He was sent home in stable condition. 